\title{
VARIABILIDADE MORFOCULTURAL E GENÉTICA DE FUNGOS ASSOCIADOS À PODRIDÃO PEDUNCULAR DO MAMÃO
}

\author{
ÂNGELA PIMENTA PERES ${ }^{1}$ \\ RENATA SILVA-MANN ${ }^{2}$ \\ MARIA DAS GRAÇAS G. C. VIEIRA ${ }^{3}$ \\ JOSÉ DA CRUZ MACHADO ${ }^{4}$
}

\begin{abstract}
RESUMO - Objetivou-se, com este trabalho, verificar a variabilidade morfocultural e genética de fungos associados à podridão peduncular do mamão (Carica papaya L.). As avaliações morfoculturais foram feitas pelo índice de crescimento micelial e características das colônias, como coloração e tipo de micélio, quando os isolados foram crescidos em diferentes meios de cultura (BDA, MDA e Czapek). A variabilidade genética foi verificada por meio de análises de AFLP. Os isolamentos foram feitos em frutos obtidos de diferentes regiões produtoras do Brasil. Foram estudados oito isolados de cada uma das três espécies mais incidentes (Colletotrichum gloeosporioi-
\end{abstract}

des, Phoma caricae-papayae e Fusarium solani). Foi verificado que os meios BDA e MDA promoveram um maior e mais rápido crescimento micelial para a maioria dos isolados testados e houve variações nas colorações das colônias desses isolados nos diferentes meios. A análise de AFLP gerou um total de 339 bandas polimórficas, indicando uma variabilidade genética entre os isolados de cada espécie fúngica, com alguns desses microrganismos formando grupos divergentes dos demais. Não foi observada uma correlação entre características morfológicas e análises de AFLP.

TERMOS PARA INDEXAÇÃO: Colletotrichum gloeosporioides, Phoma caricae-papayae, Fusarium solani, AFLP, Carica papaya.

\section{MORPHOCULTURAL AND GENETIC VARIABILITY OF FUNGI ASSOCIATED WITH STEM-END ROT OF PAPAYA}

\begin{abstract}
The objective of this work was to look at the variability between isolates of the three fungal species, Colletotrichum gloeosporioides, Fusarium solani and Phoma caricae-papayae associated with stem-end rot in papaya fruits (Carica papaya L.) which were produced in different regions of Brazil. In one trial, comparisons were made considering morphological and cultural characteristics exhibited by the fungi grown in different media: Potato dextrose agar (PDA), Papaya extract agar (PEA) and Czapek. In general, mycelial growth of all fungi was higher in
\end{abstract}

PDA and PEA and no correlation was seen between growth rates and other morphocultural characteristics such as color, colony type and others for all isolates compared. The analysis of AFLP markers revealed that there is a huge genetic variation between isolates as demonstrated by the production of 339 bands in eletrophoretic gel. With basis on genetic diversity it was possible to characterize four groups of C. gloeosporioides, F.solani and P. caricae-papayae. No correlation was seen between morphocultural characteristics and AFLP analysis.

INDEX TERMS: Colletotrichum gloeosporioides, Phoma caricae-papayae, Fusarium solani, AFLP, Carica papaya.

1. Professora, DSc. em Ciência dos Alimentos - Universidade Estadual de Goiás e Faculdade da Terra de Brasília.

2. Engenheiro Agrônomo, DSc. em Fitotecnia, Bolsista Recém-doutor - Universidade Federal de Sergipe

3. Professora Titular - Departamento de Agricultura - UNIVERSIDADE FEDERAL DE LAVRAS/UFLA - Caixa Postal 37 - 37200-000 - Lavra, MG.

4. Professor Titular - Departamento de Fitopatologia/UFLA. 


\section{INTRODUÇÃO}

A podridão peduncular do mamão (Carica papaya L.) é o resultado da colonização dos tecidos do fruto por um complexo de fungos, incluindo Colletotrichum gloeosporioides, Fusarium solani, Phoma caricae-papayae, Botryodiplodia sp, Phomopsis sp, Fusarium spp, Alternaria alternata, Stemphylium lycopercisi e Colletotrichum gloeosporioides. Esses fungos desenvolvem-se no local do corte do pedúnculo, ou nas rachaduras, ou mesmo nos ferimentos que ocorrem durante a colheita, comprometendo a qualidade do fruto (BLEINROTH, 1995).

A crescente demanda mundial por frutas tropicais tem exigido dos produtores e exportadores uma preocupação quanto à produção de frutas de melhor qualidade fitossanitária, tornando essencial o desenvolvimento de programas de controle, incluindo a diagnose prévia desses patógenos, que são problemas em póscolheita.

A caracterização morfológica é tradicionalmente empregada para a identificação de fungos fitopatogênicos e envolve análise de pigmentação das colônias, textura, forma marginal e velocidade de crescimento micelial, processo de formação, forma e tamanho de esporos (BURGESS et al., 1995), além de patogenicidade (VALIM-LABRES et al., 1997). Entretanto, essa caracterização, embora útil, é bastante limitada por causa do baixo número de caracteres passíveis de serem analisados (FUNGARO, 2000), da alta instabilidade e dependência da composição do meio utilizado, das condições de incubação e das variações intrínsecas ao patógeno.

Diante disso, as técnicas moleculares baseadas em análise de DNA têm possibilitado o desenvolvimento de métodos rápidos, sensíveis e específicos de detecção de fitopatógenos e que poderão ser utilizados num futuro próximo como parte dos programas de controle de qualidade de frutos para exportação.

Objetivou-se, com este trabalho, verificar a variabilidade morfocultural e genética dos principais fungos associados à podridão peduncular do mamão, obtidos de diferentes regiões produtoras do Brasil.

\section{MATERIAL E MÉTODOS}

\section{Obtenção e procedência dos isolados}

Utilizando-se frutos de mamoeiro obtidos de regiões produtoras dos Estados de Minas Gerais, Espírito Santo, Bahia e Amazonas, foram feitos isolamentos dos fungos presentes. Foi feita uma câmara úmida do pedúnculo, que foi previamente cortado em pedaços, desinfestado superficialmente com álcool, hipoclorito de sódio $1 \%$ e lavado em água destilada esterilizada. O material foi incubado em caixas gerbox contendo duas folhas de papel de filtro umedecidas em água destilada esterilizada, por um período de 48 horas a $20 \pm 2^{\circ} \mathrm{C}$ e fotoperíodo de 12 horas. Posteriormente, procedeu-se ao isolamento direto dos fungos, que foram transferidos para placas de Petri contendo meio BDA e incubados em câmaras de $20 \pm 2^{\circ} \mathrm{C}$, sob fotoperíodo de 12 horas. Após o crescimento dos isolados, foram feitas repicagens periódicas até a obtenção das culturas puras. Por meio de preparações em lâminas e observações ao microscópio ótico, fez-se a identificação dos organismos baseada em suas características morfológicas. De cada espécie, foram tomados aleatoriamente oito isolados dos fungos citados na literatura como associados à podridão peduncular do mamão (Tabela 1).

TABELA 1 - Procedência de isolados de $C$. gloeosporioides, $F$. solani e $P$. caricae-papayae, associados à podridão peduncular do mamão. UFLA, Lavras, MG, 2002.

\begin{tabular}{cccccc}
\hline \multicolumn{2}{c}{$\boldsymbol{F}$. solani } & \multicolumn{2}{c}{$\boldsymbol{C}$. gloeosporioides } & \multicolumn{2}{c}{ P. caricae papayae } \\
\hline Isolado & Procedência & Isolado & Procedência & Isolado & Procedência \\
\hline F-08 & Amazonas & C-10 & Bahia & A-31 & Bahia \\
F-25 & Bahia & C-26 & Bahia & A-15 & Espírito Santo \\
F-29 & Bahia & C-27 & Bahia & A-20 & Espírito Santo \\
F-33 & Bahia & C-32 & Bahia & A-24 & Espírito Santo \\
F-01 & Espírito Santo & C-34 & Bahia & A-42 & Minas Gerais \\
F-18 & Espírito Santo & C-12 & Espírito Santo & A-43 & Minas Gerais \\
F-36 & Espírito Santo & C-17 & Espírito Santo & A-44 & Minas Gerais \\
F-40 & Minas Gerais & C-19 & Espírito Santo & A-45 & Minas Gerais \\
\hline
\end{tabular}

Ciênc. agrotec., Lavras. V.27, n.5, p.1053-1062, set./out., 2003 


\section{Variabilidade morfocultural dos isolados, in vitro}

Os isolados de $P$. caricae-papayae, $C$. gloeosporioides e $F$. solani foram cultivados por 7 dias em meio BDA e, após esse período, um disco de meio contendo micélio foi retirado da periferia da colônia e transferido para o centro de novas placas de Petri de 9 $\mathrm{cm}$ de diâmetro contendo o meio a ser testado. Os fungos foram cultivados em meio BDA, meio Czapek e meio MDA (200 g mamão, $20 \mathrm{~g}$ ágar e $20 \mathrm{~g}$ dextrose/1000 mL de água), em câmara com temperatura de $20 \pm 2{ }^{\circ} \mathrm{C}$ e fotoperíodo de 12 horas.

Durante um período de 7 dias, foram feitas avaliações da taxa de crescimento dos isolados, a intervalos de 24 horas, medindo-se dois diâmetros ortogonais entre si na face inferior das placas, até que uma das placas (repetição) de cada um dos isolados apresentasse o maior diâmetro em cada meio. De posse dos dados, foram calculados os índices de crescimento micelial segundo a fórmula:

$$
\mathrm{ICM}=\frac{\mathrm{C}_{1}}{\mathrm{~N}_{1}}+\frac{\mathrm{C}_{2}}{\mathrm{~N}_{2}} \cdots+\frac{\mathrm{C}_{\mathrm{N}}}{\mathrm{N}_{\mathrm{N}}}
$$

em que:

ICM= índice de crescimento micelial

$\mathrm{C}_{1}=$ crescimento micelial no primeiro dia

$\mathrm{N}_{1}=$ número de dias

As características morfológicas utilizadas na análise dos isolados foram: (a) coloração e tipo de micélio (aspectos de densidade e homogeneidade das hifas); (b) posição do micélio em relação ao substrato; (c) presença e ausência de anelamento.

A coloração das culturas foi descrita conforme o sistema de Munsell Color Company (1975) de notação de cores.

\section{Cultivo dos isolados e extração do DNA ge-} nômico

Oito isolados de cada um dos três gêneros em estudo foram cultivados em meio BDA por 7 dias. Após esse período, um disco de BDA de $5 \mathrm{~mm}$ de diâmetro foi transferido para erlenmeyer contendo $150 \mathrm{~mL}$ de meio líquido (MILLS et al., 1994). Os erlenmeyers com meio líquido contendo o isolado foram mantidos em agitador com temperatura de $20^{\circ} \mathrm{C}$ sob agitação, no escuro, por mais 7 dias. Foram feitas quatro repetições por isolado. Para posterior extração do DNA, o micélio produzido foi filtrado com auxílio de uma bomba de vácuo, em câmara de fluxo laminar, e liofilizado, por 48 horas, sob temperatura de $-40^{\circ} \mathrm{C}$, pressão $10^{-1} \mathrm{mbar}$. As extrações do DNA nuclear foram executadas empregando Kit DNeasy Qiagen (1999).

\section{Amplificação do DNA}

As análises de AFLP (polimorfismo de tamanho de fragmentos amplificados) foram realizadas na Brigham Young University-Utah (USA) usando-se o protocolo da Life Technologies (1999). A amplificação seletiva foi feita com primers Eco $R I+2$ pares de bases e $\mathrm{MseI}+2$ pares de base (CHEUNG, 2000), para as diferentes combinações dos primers (Tabela 2), sendo os primers Eco RI marcados com radioisótopo fósforo 32.

Os produtos das amplificações foram carreados por 2 horas e 30 minutos em gel desnaturante de poliacrilamida $12,5 \%$, que sofreram previamente uma précorrida por 15 minutos. Os géis, ao final da migração, foram secos em papel Whatman 3MM. Subseqüentemente, autoradiogramas foram expostos por 1 a 7 dias para visualização dos fragmentos de AFLP.

Para a análise dos dados, foram consideradas a presença e ausência de fragmentos de AFLP, os quais foram transferidos para uma matriz onde a ausência de uma dada banda foi denominada por 0 e a presença, por 1. As diferenças de intensidade de bandas não foram consideradas, uma vez que o marcador tipo AFLP é dominante. As análises foram desenvolvidas com o programa NTSYS-PC 2.1 (RHOLF, 2000). As similaridades entre os genótipos analisados foram calculadas com o Coeficiente de Dice (1945). Os isolados foram agrupados usando a análise de agrupamento UPGMA (unweighted pair-group method, arithmetic average) (RHOLF, 2000).

TABELA 2 - Combinação de primers (Gibco BRL) utilizados no estudo sobre variabilidade de isolados associados à podridão peduncular do mamão. UFLA, Lavras-MG, 2002.

\begin{tabular}{ccc}
\hline \multirow{2}{*}{ Pré Amplificação } & \multicolumn{2}{c}{ Combinação de primers } \\
& EcoRI & MseI \\
\hline AC & EAT & MCG \\
AC & EAT & MCA \\
AC & EAT & MCG \\
AC & EAT & MCC \\
AC & EAA & MCA \\
AC & EAA & MCC \\
AC & EAA & MCT \\
AC & EAA & MCG \\
\hline
\end{tabular}




\section{Delineamento experimental e análise estatística}

Para as taxas de crescimento micelial, o delineamento experimental foi inteiramente casualizado, constando de 4 repetições por isolado, para cada meio de cultura testado.

\section{RESULTADOS E DISCUSSÃO}

\section{Índice de crescimento micelial dos isolados}

Uma maior homogeneidade no índice de crescimento micelial foi obtida com $C$. gloeosporioides crescido em meio de mamão (MDA), onde foram observadas médias elevadas e não foram observadas diferenças significativas entre os isolados. De maneira geral, não houve diferenças significativas entre os meios de cultura, e o meio Czapek permitiu um menor crescimento da maioria dos isolados de $C$. gloeosporioides estudados. O isolado C-17 cresceu menos em meio BDA e mais em meio Czapek, em relação aos demais. Isolados, como o C-32 e o C-34, mostraram altos índices de crescimento micelial, principalmente em meio BDA e MDA, inferindo-se que os isolados podem se comportar diferentemente no meio de cultura in vitro ou mesmo em condições de substrato do hospedeiro, durante o processo de patogênese (Tabela 3).

Os isolados de F. solani, em sua maioria, desenvolveram-se mais lentamente em meio Czapek e comportaram-se semelhantemente nos meios MDA e BDA. O isolado F-40 teve um destacado crescimento em meio BDA, que se mostrou estatisticamente diferente dos demais meios. De modo geral, o meio BDA propiciou um crescimento homogêneo para $F$. solani (Tabela 3 ).

Os isolados de $P$. caricae-papayae, em sua maioria, cresceram mais rapidamente em meio BDA e MDA. O meio Czapek promoveu o crescimento mais lento desses isolados. Foi observado um padrão de crescimento similar entre os isolados A-43, A-44 e A-45, procedentes do norte de Minas Gerais e os isolados A15 e A-31, procedentes do Espírito Santo e Bahia, respectivamente (Tabela 3 ).

TABELA 3 - Índice de crescimento micelial dos isolados de $C$. gloeosporioides, $F$. solani e $P$. caricae-papayae associados à podridão peduncular do mamão, em diferentes meios de cultura. UFLA, Lavras, MG, 2002.

\begin{tabular}{|c|c|c|c|c|c|c|c|c|c|c|c|}
\hline \multicolumn{4}{|c|}{ C. gloeosporioides } & \multicolumn{4}{|c|}{ F. solani } & \multicolumn{4}{|c|}{ P. caricae-papayae } \\
\hline \multicolumn{2}{|c|}{ Isolado } & \multicolumn{2}{|c|}{ Meio de cultura } & \multirow{2}{*}{\multicolumn{2}{|c|}{$\frac{\text { Isolado }}{\text { BDA }^{1}}$}} & \multicolumn{2}{|c|}{ Meio de cultura } & \multirow{2}{*}{\multicolumn{2}{|c|}{$\frac{\text { Isolado }}{\text { BDA }^{1}}$}} & \multicolumn{2}{|c|}{ Meio de cultura } \\
\hline & BDA $^{1}$ & $\mathbf{M D A}^{1}$ & Czapek $^{1}$ & & & MDA $^{1}$ & Czapek $^{1}$ & & & MDA $^{1}$ & Czapek $^{1}$ \\
\hline $10^{2}$ & $6,83 \mathrm{AB}$ a & $6,76 \mathrm{~A} \mathrm{a}$ & $4,55 \mathrm{~B} \mathrm{~b}$ & $01^{2}$ & $7,00 \mathrm{~B} \mathrm{a}$ & $6,91 \mathrm{Ca}$ & $6,27 \mathrm{BC} \mathrm{a}$ & $15^{2}$ & 7,63 ABa & $7,67 \mathrm{AB}$ a & $7,14 \mathrm{AB}$ a \\
\hline 12 & $7,01 \mathrm{AB} a b$ & $7,50 \mathrm{~A} \mathrm{a}$ & $6,01 \mathrm{AB} b$ & 08 & $7,14 \mathrm{~B} \mathrm{a}$ & $6,82 \mathrm{Ca}$ & $6,79 \mathrm{AB}$ a & 20 & $6,40 \mathrm{BC}$ a & $5,02 \mathrm{D} \mathrm{b}$ & $4,21 \mathrm{D} \mathrm{b}$ \\
\hline 17 & $5,63 \mathrm{~B} \mathrm{~b}$ & $7,46 \mathrm{~A} \mathrm{a}$ & $6,48 \mathrm{~A}$ ab & 18 & $7,38 \mathrm{~B} \mathrm{a}$ & $7,05 \mathrm{BC} \mathrm{a}$ & $6,99 \mathrm{AB}$ a & 24 & $6,13 \mathrm{CD}$ a & $6,40 \mathrm{BCD}$ a & $4,95 \mathrm{CD} \mathrm{b}$ \\
\hline 19 & $6,88 \mathrm{AB}$ ab & $7,36 \mathrm{~A} \mathrm{a}$ & $5,94 \mathrm{AB} \mathrm{b}$ & 25 & $7,43 \mathrm{~B} \mathrm{a}$ & 7,99 $\mathrm{AB}$ a & $6,52 \mathrm{ABC} b$ & 31 & $7,15 \mathrm{ABC}$ a & $7,72 \mathrm{~A} \mathrm{a}$ & $7,26 \mathrm{~A} \mathrm{a}$ \\
\hline 26 & $6,16 \mathrm{~B} \mathrm{a}$ & $6,11 \mathrm{~A} \mathrm{a}$ & $5,17 \mathrm{AB}$ a & 29 & $6,60 \mathrm{~B} \mathrm{ab}$ & 7,31 $\mathrm{ABC}$ a & $6,39 \mathrm{ABC} b$ & 42 & $4,96 \mathrm{D} \mathrm{b}$ & $6,09 \mathrm{CD}$ a & $5,90 \mathrm{BC} \mathrm{ab}$ \\
\hline 27 & $5,78 \mathrm{~B} \mathrm{a}$ & $6,09 \mathrm{~A} \mathrm{a}$ & $5,80 \mathrm{AB}$ a & 33 & 7,54 B ab & $8,30 \mathrm{~A} \mathrm{a}$ & 7,38 A b & 43 & $7,97 \mathrm{~A} \mathrm{a}$ & $7,54 \mathrm{AB} a b$ & $6,96 \mathrm{AB} b$ \\
\hline 32 & $8,16 \mathrm{~A} \mathrm{a}$ & 7,61 A a & $5,45 \mathrm{AB} \mathrm{b}$ & 36 & $6,57 \mathrm{~B} \mathrm{a}$ & 7,09 BC a & $5,57 \mathrm{Cb}$ & 44 & $7,17 \mathrm{ABC}$ a & $6,50 \mathrm{ABC}$ a & $7,19 \mathrm{AB}$ a \\
\hline 34 & $7,04 \mathrm{AB}$ a & $7,46 \mathrm{~A} \mathrm{a}$ & $4,46 \mathrm{~B} \mathrm{~b}$ & 40 & $8,85 \mathrm{~A} \mathrm{a}$ & 7,58 ABC b & $7,24 \mathrm{AB} b$ & 45 & $7,55 \mathrm{AB}$ a & $6,79 \mathrm{ABC}$ a & 7,37 A a \\
\hline $\mathrm{CV}^{3}$ & & & $11,54 \%$ & $\mathrm{CV}^{3}$ & & & $6,53 \%$ & $\mathrm{CV}^{3}$ & & & $8,79 \%$ \\
\hline
\end{tabular}

${ }^{1}$ Médias seguidas de pelo menos uma mesma letra maiúscula nas colunas, para cada meio de cultura, não diferem entre si pelo teste de Tukey $(\mathbf{P}>0,05)$.

${ }^{2}$ Médias seguidas de pelo menos uma letra minúscula nas linhas, para cada isolado, não diferem entre si pelo teste de Tukey $(\mathbf{P}>\mathbf{0 , 0 5})$.

${ }^{3}$ Coeficiente de variação

Ciênc. agrotec., Lavras. V.27, n.5, p.1053-1062, set./out., 2003 
Verifica-se que houve uma grande variação quanto à velocidade de crescimento micelial entre os isolados associados à podridão peduncular de frutos de mamoeiro, quando cultivados nos meios de cultura estudados. Reese et al. (1968), English e Albersheim (1993) afirmam que o crescimento dos fungos pode ser estimulado quando os mesmos crescem em meio de cultura contendo monossacarídeos. No entanto, alguns autores discutem que o aumento nos níveis de açúcares do meio normalmente reprime a atividade de alguns microrganismos. Esse fato pode justificar, por exemplo, o crescimento lento em meio MDA para isolados como F-01 e A-20, em relação aos demais isolados da espécie, uma vez que, além da dextrose, esse meio contava com a fonte de açúcar proveniente do mamão. Entretanto, para a maioria dos isolados estudados, baseado nas análises de índice de crescimento micelial, pode-se afirmar que os meios BDA e MDA, além de permitirem uma maior homogeneidade de ICM para a maioria dos isolados, favoreceram o crescimento mais rápido dos fungos, quando comparados ao meio Czapek.

Em relação à procedência dos isolados (Tabela 1), nota-se que o ICM foi também variável entre os isolados, mesmo naqueles provenientes de um mesmo Estado. Uma explicação provável para esses resultados pode estar no fato de que alguns isolados, embora oriundos de um mesmo Estado, foram obtidos a partir de frutos produzidos em localidades com características edafoclimáticas distintas nos Estados amostrados ou em lavouras com manejos diferentes. Assim, pode-se afirmar que o índice de crescimento micelial não foi suficiente para estabelecer qualquer correlação entre essa variável e a origem geográfica dos isolados, inferindo-se que outros fatores podem estar relacionados com a variabilidade. Esses dados estão em concordância com Valim-Labres et al. (1997), que sugerem que a diversidade de microrganismos não é ocasionada unicamente por pressões do ambiente decorrentes de diferenças geográficas, como temperatura, umidade relativa do ar e fotoperíodo. Neste trabalho, verificou-se que a variabilidade dos isolados pode ser influenciada por algum fator intrínseco ao patógeno, genótipo do hospedeiro, ou interação entre esses fatores, concordando com dados de Teixeira (2001), que não observou correlação entre grupos de similaridade genética e origem geográfica de isolados de Acremonium strictum, sugerindo que dificilmente a expressão dos aspectos morfofisiológicos é condicionada por genes únicos.

\section{Variabilidade morfocultural das colônias dos isolados}

Observou-se a ocorrência de vários tipos de micélio em diferentes isolados de uma mesma espécie obtidos de frutos de mamoeiro. Verificou-se também uma mudança na cor e tipo de micélio de acordo com o meio de cultura utilizado, o que evidencia uma grande variabilidade existente entre isolados quando cultivados dentro de um mesmo meio e entre os diferentes meios.

Os isolados de F. solani, em sua maioria (75\%), apresentaram micélio aéreo, quando crescidos em MDA e Czapek. Cinqüenta por cento dos isolados de C. gloeosporioides, em meio BDA, tiveram a característica de micélio superficial, compacto e homogêneo e anelamento. Em meio MDA, houve uma distribuição equitativa entre os micélios aéreos e escassos para isolados de C. gloeosporioides.

Em Czapek, a maioria dos isolados de $P$. caricae-papayae apresentou micélio superficial, compacto e homogêneo, ao passo que em BDA, esses isolados formaram micélio aéreo, denso, floculoso e abundante. Os isolados do norte de Minas (A-42, A43 e A-45) mostraram padrão similar, com micélio aéreo, denso, floculoso e abundante em BDA. O isolado A-44, também do norte de Minas Gerais, apresentou micélio mais ralo e superficial em MDA.

De maneira geral, foi possível verificar que poucos isolados comportaram-se igualmente, quando crescidos nos três meios de cultura. Esse fato pode indicar um comportamento diferente entre os isolados, de acordo com a fonte de nutriente à qual têm acesso. Meio de cultura artificial, como o Czapek, proporcionou o crescimento de isolados com características de crescimento superficial, frouxo e homogêneo, enquanto no MDA, o micélio cresceu aéreo, ralo, floculoso e escasso. $\mathrm{O}$ meio BDA favoreceu o crescimento de isolados com características de micélio aéreo, denso, floculoso e abundante, principalmente para isolados de $F$. solani.

Quanto às colorações das colônias dos isolados nos diferentes meios de cultura, o meio BDA favoreceu o crescimento de isolados com intensidade de coloração mais forte, ao passo que no MDA, os isolados apresentaram-se com os tons bem mais claros. Os isolados de $F$. solani cultivados em meio BDA mostraram-se com tons, em sua maioria, laranja-pálido a róseos. Os isolados de $P$. caricae-papayae tinham tons amarronzados e os isolados de $C$. gloeosporioides tons amarelados. No meio Czapek, os isolados cresceram em tonalidades que variaram de róseos muito claros a branco. Em relação 
ao MDA, não houve uma coloração que predominasse entre as espécies, e no MDA, a maioria dos isolados cultivados mostraram-se com colorações bastante pálidas.

Neste trabalho, não foi possível formar grupos muito distintos de isolados, apenas por meio de coloração e outras características miceliais. Entretanto, em alguns trabalhos envolvendo espécies de Colletotrichum, tem sido sugerida a análise de algumas dessas características para identificação de grupos associados à patogenicidade. Entre esses trabalhos, encontram-se estudos de Bernstein et al. (1995) com C. gloeosporioides isolados de pêssego, maçã e outros hospedeiros, nos quais conseguiram separar dois grupos morfologicamente distintos desse fungo por meio de colorações de colônias e outros aspectos. Entretanto, algumas características morfológicas são subjetivas, sendo portanto, dependentes da interpretação de cada autor.

\section{Variabilidade genética dos isolados}

As análises de AFLP geraram um total de 339 bandas polimórficas para as diferentes combinações de primers. As diferentes bandas geradas apresentaram tamanhos que variaram de 30 a 330 pares de bases. Verificou-se que algumas bandas foram exclusivas para os diferentes genótipos fúngicos. Essas marcas futuramente poderão ser utilizadas no desenho de primers específicos, facilitando o processo de detecção e identificação de fitopatógenos, previamente à comercialização de frutos para exportação.

As análises de AFLP para isolados como o A-43 e o C-10 ficaram comprometidas, em razão da degradação do DNA das amostras, o que impossibilitou a extração do material genético.

Os isolados de $P$. caricae-papayae apresentaram similaridade média de $62 \%$ e formaram grupos bastante distintos, mesmo entre aqueles isolados de mesma procedência (Figura 1), sendo os agrupamentos mais divergentes compostos pelos isolados A-31, A-24 e A-44, de procedências diferentes, e com características miceliais (coloração, topografia, textura) distintas. A variabilidade observada para esses isolados pode ser decorrente de uma recombinação que eventualmente ocorra em regiões de cultivo, em função de as estruturas dos patógenos permanecerem no local de uma safra para outra. Huang et al. (1997) discutem que infecções múltiplas que ocorrem no campo têm um impacto importante na evolução dos patógenos, sendo um pré-requisito para a recombinação sexual ou parasexual. Jeffries et al. (1990) reforçam que a heterocariose e a parassexualidade são fatores cruciais na determinação da heterogeneidade fenotípica dentro de um grupo de isolados ou espécie.

Diante disso, sugere-se que recombinação genética entre os microrganismos pode ocorrer em regiões onde a produção de mamão é intensiva.

Os isolados de $F$. solani formaram dois grupos bastante distintos, e o isolado F-01 apresentou uma similaridade média de $24 \%$ em relação aos demais, e o F18, 30\% (Figura 2). É válido lembrar que esses dois isolados, apesar de pouco similares entre si, com $24 \%$ de similaridade, têm a mesma procedência, o que sugere a existência de variabilidade genética numa mesma região. Nota-se que, quando cultivados em meio BDA, MDA e Czapek, esses isolados comportaram-se também diferentemente quanto ao índice de crescimento micelial e colorações de colônias. Trabalhos de Kaufmann e Weidemann (1996) levantam uma explicação provável para a variabilidade em fitopatógenos, uma vez que sugerem a ocorrência de reprodução sexuada ou mesmo outros mecanismos de recombinação genética.

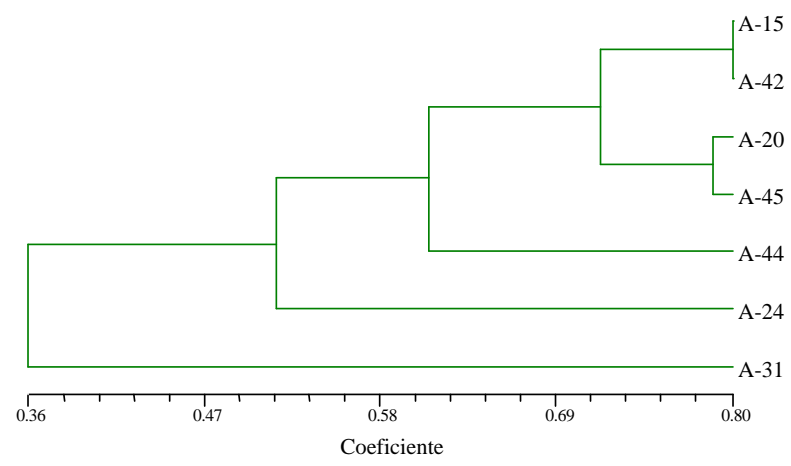

FIGURA 1 - Dendrograma de similaridade genética entre isolados de Phoma caricae-papayae associados à podridão peduncular do mamão. UFLA, Lavras, MG, 2002.

Ciênc. agrotec., Lavras. V.27, n.5, p.1053-1062, set./out., 2003 


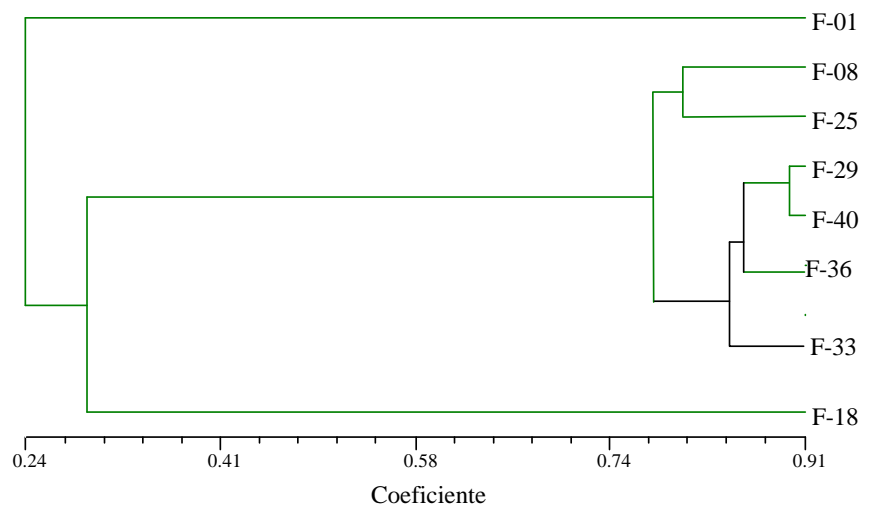

FIGURA 2 - Dendrograma de similaridade genética entre isolados de Fusarium solani associados à podridão peduncular do mamão. UFLA, Lavras, MG, 2002.

Vários estudos sobre a variabilidade de Fusarium têm sido conduzidos. Savelkoul et al. (2000) citam trabalhos sobre variações genéticas intra e interespecífica de espécies de Fusarium por AFLP. Resultados de trabalhos de Kerényi et al. (1997) envolvendo uma correlação parcial entre compatibilidade micelial, RAPD e as regiões geográficas de procedência dos isolados indicaram um moderado nível de variabilidade genética entre as regiões geográficas estudadas (média de $80 \%$ de similaridade). Os autores afirmam que a combinação de métodos moleculares e tradicionais permite relacionar com segurança subdivisões intraespecíficas de fungos no estádio assexual, como Fusarium, e sugerem que esse patógeno, por ser um invasor secundário de uma grande quantidade de plantas, nunca será alvo de uma pressão de seleção num mesmo hospedeiro. No presente trabalho, isolados de $F$. solani, como o F-25, F-29 e F-33, procedentes do mesmo Estado (Bahia), apresentaram alta similaridade (média de 80\%), concordando com resultados obtidos por Kerényi et al. (1997) (Figura 2).

Quanto aos isolados de C. gloeosporioides, verificou-se a formação de um grupo distinto pelo isolado C-17 que, pelos coeficientes de similaridade, mostrou-se bem mais dissimilar aos demais isolados de C. gloeosporioides, com $34 \%$ de similaridade, enquanto o restante dos isolados apresentou média de $84 \%$ de similaridade (Figura 3). Infere-se, com isso, que o isolado C-17 possui no seu genoma seqüências bastante divergentes daquelas dos outros isolados dessa espécie. Além desse grupo, verifica-se a formação de outro grupo pelo isolado C-12, em relação aos demais isolados, com $80 \%$ de similaridade. É interessante lembrar que esses dois isolados têm a mesma origem geográfica, indicando, conforme já comentado, que outros fatores inerentes ao microrganismo ou hospedeiros do mesmo podem exercer influência sobre o genótipo dos isolados.

Por este estudo, verificou-se que a análise molecular foi distinta da caracterização morfocultural. Freeman et al. (2000) caracterizaram vários isolados de Colletotrichum spp. a partir de espécies de frutos diferentes, por meio de métodos moleculares, e compararam com a identificação morfológica. Os autores concluíram que o agrupamento filogenético baseado na sequiência de dados não apresentou relação com a morfologia dos conídios. Dessa forma, embora a morfologia dos conídios seja um dos critérios mais importantes para a delimitação das espécies, a classificação baseada nesse critério é questionável, tendo em vista a possibilidade de formas e tamanhos diferentes de conídios estarem presentes numa mesma população.

Diante disso, estudos envolvendo técnicas moleculares podem ser também complementares às técnicas tradicionalmente empregadas em taxonomia. A delimitação de espécies de Colletotrichum, segundo Sutton (1980), é baseada em métodos tradicionais, como tamanho e forma de conídios, características das colônias, presença de escleródios, morfologia do apressório e especificidade do hospedeiro. Em trabalhos posteriores, Sutton (1992) ressalta que nenhum progresso nas relações genéticas, para a identificação de fungos fitopatogênicos, tem sido alcançado, baseando-se somente em caracteres morfológicos. Dessa forma, a análise molecular do genoma desses microrganismos é pertinente, uma vez que algumas características podem ser dependentes de fatores como meio de cultura, conforme sugerido por TeBeest et al. (1989). 


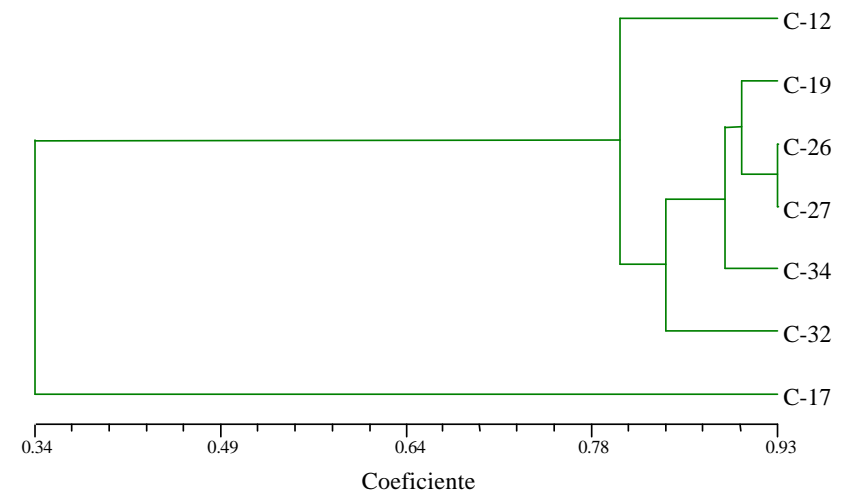

FIGURA 3 - Dendrograma de similaridade genética entre isolados de Colletotrichum gloeosporioides associados à podridão peduncular do mamão. UFLA, Lavras, MG, 2002.

Pelos resultados deste trabalho, reforça-se a idéia de que o uso de métodos moleculares aliados aos parâmetros tradicionais são fundamentais na identificação eficiente de espécies fúngicas e variabilidade entre as mesmas, sugerindo uma revisão nas características que tradicionalmente classificam esse gênero, como coloração e formato de colônias, tamanho e forma de conídios, etc. Em concordância com este trabalho, O’Neill et al. (1996) afirmam que a classificação das relações genéticas entre as várias espécies que compõem o gênero Colletotrichum, usando características morfológicas, é difícil, por causa das alterações que podem ocorrer nas características dos isolados, quando mantidos sob diferentes condições de cultivo em meio artificial ou de campo, o que pode afetar, por exemplo, a pigmentação, tamanho e estrutura do acérvulo e septos nas setas. Assim, a combinação dos métodos moleculares e morfológicos na identificação de patógenos ou variabilidade entre os mesmos torna-se uma realidade, uma vez que somente com a utilização adequada desses métodos pode-se chegar a resultados confiáveis.

A técnica AFLP vem sendo utilizada com sucesso para analisar o genoma de várias espécies de fungos, entre as quais Cyphomyrmex minutus, um fungo micorrízico; Fusarium spp.; Phytophthora infestans; fungos de relevância médica como Aspergillus fumigatus e Candida spp. (SAVELKOUL et al., 2000); Colletotrichum gossypii e Colletotrichum gossypii var. cephalosporioides (SILVA-MANN et al., 2002). Pelas variáveis estudadas nesta pesquisa, constata-se que uma série de eventos podem estar envolvidos na expressão de caracteres morfoculturais, bem como de virulência, o que nem sempre pode ser amostrado pela análise genômica de sequiências amplificadas por técnicas como os marcadores moleculares de AFLP, uma vez que as inúmeras características dos microrganismos podem ser controladas por vários genes. Esse fato reforça a idéia de que a caracterização morfológica, aliada à análise do genoma, são fundamentais para a identificação e caracterização de fungos fitopatogênicos.

\section{CONCLUSÕES}

Entre as espécies fúngicas do complexo da podridão peduncular do mamão, verificou-se uma ampla variabilidade morfológica entre isolados, não havendo, porém, uma correlação com essas características e análises de AFLP.

Os isolados de $C$. gloeosporioides, $F$. solani e $P$. caricae-papayae mostraram comportamento variável em diferentes meios de cultura, tornando difícil a correlação entre similaridade fenotípica, genotípica e origem dos isolados.

Foi demonstrada uma alta variabilidade genética entre isolados de $P$. caricae-papayae e $C$. gloeosporioides, e moderada variabilidade para isolados de $F$. solani.

O par de isolados mais divergente de $C$. gloeosporioides apresentou similaridade de $34 \%$, sendo procedentes de uma mesma região, enquanto o par de isolados de $F$. solani mais divergente apresentou similaridade de $24 \%$, sendo também de mesma procedência. O isolado mais divergente de $P$. caricae-papayae apresentou $36 \%$ de similaridade com os demais isolados, sendo de procedência distinta dos demais isolados. 
Não foi verificada uma correlação entre procedência dos isolados e similaridade genética entre os mesmos, inferindo-se que nem sempre isolados de mesma procedência são mais similares.

\section{REFERÊNCIAS BIBLIOGRÁFICAS}

BERNSTEIN, B.; ZEHR, E. I.; DEAN, R. A. Characteristics of Colletotrichum from peach, apple, pecan, and other hosts. Plant Disease, Saint Paul, v. 79, n. 5, p. 478-483, May 1995.

BLEINROTH, E. W. In: GAYET, J. P.; BLEINROTH, E. W.; MATALLO, M.; GARCIA, E. E. C.; GARCIA, A. E.; ARDITO, E. F. G.; BORDIN, M. R. Mamão para exportação: procedimentos de colheita e póscolheita. Brasília: EMBRAPA-FRUPEX, 1995. 38 p.

BURGESS, T.; MALAJCZUK, N.; DELL, B. Variation in Pisolithus and basidiospore morphology, culture characteristics and analysis of polypeptides using 1D SDS-PAGE. Mycological Research, Edinburg, v. 99, n. 1, p. 1-13, Jan. 1995.

CHEUNG, W. D. AFLP DNA fingerprinting of Colletotrichum spp. Disponível em: <http://wpi.edu/wcheung/ rppaper>. Acesso em: 10 nov. 2000.

DICE, L. R. Measures of the amount of ecologic association between species. Ecology, Washington, v. 26, n. 3, p. 297-302, 1945.

ENGLISH, P. D.; ALBERSHEIM, P. Host-pathogen interactions in postharvest diseases. In: LIEBERMAN, M. (Ed.). Post-harvest physiology and crop preservation. [S.1.]: Plenum, 1993.

FREEMAN, S.; MINZ, D.; JURKEVITCH, E.; MAYMON, M.; SHABI, E. Molecular analysis of Colletotrichum species from almond and other fruits. Phytopathology, Saint Paul, v. 90, n. 6, p. 608-614, June 2000

FUNGARO, M. H. P. PCR na micologia. Biotecnologia - Ciência \& Desenvolvimento, Uberlândia, v. 3, n. 14, p. 12-16, maio/jun. 2000.

HUANG, R.; GALPERIN, M.; LEVY, Y.; PERLTREVES, R. Genetic diversity of Fusarium moniliforme detected by vegetative compatibility groups and random amplified polymorphic DNA markers. Plant Pathology, Edinburg, v. 46, n. 6, p. 871-881, Dec. 1997.
JEFFRIES, P.; DODD, J. C.; JEGER, M. J.; PLUMBLEY, R. A. The biology and control of Colletotrichum species on tropical fruit crops. Plant Pathology, Edinburg, v. 39, n. 3, p. 343-366, Sept. 1990.

KAUFMANN, P. J.; WEIDEMANN, G. J. Isozyme analysis of Colletotrichum gloeosporioides from five host genera. Plant Disease, Saint Paul, v. 80, n. 11, p. 1289-1293, Nov. 1996.

KERÉNYI, Z.; TÁBORHEGYI, É.; POMÁZI, A.; HORNOK, L. Variability amongst strains of Fusarium poae assessed by vegetative compatibility and RAPD polymorphism. Plant Pathology, Edinburg, v. 46, n. 6, p. 882-889, Dec. 1997.

LIFE TECHNOLOGIES. AFLP Analysis System I and AFLP Started Primer Kit. [S.1.]: GIBCO, 1999. 19 p.

MILLS, P. R.; SREENIVASAPRASAD, S.; BROWN, A. E. Detection of the antracnose pathogen Colletotrichum. In: SCHOTS, A.; DEWEY, F. M.; OLIVER, R. Modern assays for plant pathogenic fungi: identification, detection and quantification. Wallingford: Redwood, 1994. p. 183-189.

MUNSELL COLOR COMPANY. Munsell soil color charts. Baltimore, 1975.

O'NEILL, N. R. Pathogenic variability and host resistence in the Colletotrichum trifolii/Medicago pathosystem. Plant Disease, Saint Paul, v. 80, n. 4, p. 450-457, Apr. 1996.

QIAGEN, D. Neasy plant mini handbook: for isolation from plant tissue. New York: [s.n.], 1999. 16 p.

REESE, E. T.; MAGUIRE, A. H.; PARRISH, F. W. Glicosidases and exo-glucanases. Canadian Journal of Biochemistry, Ottawa, v. 46, n. 1, p. 25-36, Jan. 1968.

RHOLF, F. Numerical taxonomy and multivariate analysis system: version 2.10. New York: [s.n.], 2000.

SAVELKOUL, P. H. M.; AARTS, H. J. M.; HAAS, J. de; DIJKSHOORN, L.; DUIM, B.; OTSEN, M.; RADEMAKER, J. L. W.; SCHOULS, L.; LENSTRA, J. A. Amplified-fragment length polymorphism analysis: the state of an art. Disponível em: <http://jcm.asm.org/egi/ content/full>. Acesso em: 29 nov. 2000. 
SILVA-MANN, R.; MACHADO, J. da C.; TeBEEST, D. O.; SHILLING, C. W.; HOPKINS, R. L.; CARVALHO, K. C. S.; VIEIRA, M. G. C. Estudo da WEIDEMANN, G. J. The number of nuclei in spores of variabilidade genética de isolados do complexo three species of Colletotrichum. Mycologia, Bronx, v. Colletotrichum associados a sementes de algodão por 81, n. 1, p. 147-149, Jan./Feb. 1989.

meio de técnicas moleculares e inoculação em plantas.

Fitopatologia Brasileira, Brasília, v. 27, n. 1, p. 2732, jan./fev. 2002.

SUTTON, B. C. The genus Glomerella and its anamorph Colletotrichum. In: BAILEY, J. A.; JEGER, M. J. Colletotrichum: biology, pathology and control. Wallingford: Redwood, 1992. 388 p.

SUTTON, B. C. The Coelomycetes. Kew: Commonwealth Mycological Institute, 1980.

TEIXEIRA, H. Variabilidade de Acremonium strictum e sua transmissibilidade e efeitos em sementes de milho (Zea mays L.). 2001. 127 p. Tese (Doutorado em Fitopatologia) - Universidade Federal de Lavras, Lavras, 2001.

VALIM-LAMBRES, M. E.; PRESTES, A. M.; SAND, S. van der; MATSUMURA, A. T. S. Variação no aspecto cultural, morfologia e virulência em isolados de Bipolaris sorokiniana de trigo. Fitopatologia Brasileira, Brasília, v. 22, n. 4, p. 483-487, dez. 1997. 